\title{
The value of a rural service learning experience for final year undergraduate occupational therapy students
}

\author{
Elize Janse van Rensburg, B Occ Ther (UFS), M Occ Ther (UFS) \\ Lecturer, Department of Occupational Therapy, University of the Free State
}

\section{Sanetta H.J. Du Toit, M Occ Ther (UFS), MSc (University of Exeter, UK), PhD (UFS)}

Lecturer, Discipline of Occupational Therapy, Faculty of Health Sciences, The University of Sydney, Australia. Affiliated lecturer, Department of Occupational Therapy, University of the Free State

Introduction: Service learning is a form of practice learning employed by occupational therapy training programmes in South Africa, through which the call for universities to engage with communities is also heeded. Rural areas of South Africa have limited access to occupational therapy services, thus service learning engagements with rural communities is a pertinent consideration for occupational therapy training programmes. However, given the high resource demands of rural service learning engagements it was necessary to ascertain the value that such a rural service learning experience has for occupational therapy students.

Method: A qualitative, descriptive enquiry design was utilised to describe the value of a rural service learning experience for final year undergraduate occupational therapy students. A purposive sample of twelve students who participated in a rural service learning placement in one year was drawn. A nominal group was conducted with nine of these students who were available for participation, and deductive qualitative content analysis of all twelve students' written journals submitted throughout the year was performed.

Results: Findings highlighted various ways in which this experience enhanced students' understanding of the dynamics of working in a rural community setting, and provided them with opportunities for personal and professional growth.

Conclusion: The rural service learning experience was a valuable and transformative learning opportunity for students. Future considerations should include expanding these opportunities and establishing a service learning model based on the insights gained.

Key words: Occupational therapy, practice learning, rural context, transformative learning, community engagement, community-based education

\section{INTRODUCTION}

Service learning as a form of practice learning ${ }^{\prime}$ in occupational therapy education holds many potential benefits for students. Academic learning, professional and personal development as well as an enhanced sense of social responsibility are primary objectives of service learning ${ }^{2,3,4,5}$. Research into the effects of service learning on student development evidences that these objectives are fairly consistently attained $d^{6,7,8,9}$

In the South African higher education context, scholarly community engagement such as service learning was mandated by the Education White Paper 3 of 1997, the National Plan on Higher Education of 200I and the Higher Education Quality Committee Criteria for Programme Accreditation ${ }^{10}$. One of the motivations behind this mandate was to assist previously disadvantaged communities through university resources ${ }^{\prime \prime}$. This is a particularly relevant consideration in the "underfund[ed]" 12:1 public health system, as many South Africans do not have access to occupational therapy services with only 2.6 occupational therapists per 100000 people working in the public health system ${ }^{13}$. Access to occupational therapy services is thus potentially enhanced through occupational therapy service learning engagements with communities.

Rural areas of South Africa are specifically disadvantaged by the limited availability of qualified health care professionals ${ }^{14}$. As a result, access to occupational therapy services is particularly limited in rural settings, and service learning engagements with rural communities would therefore be a pertinent consideration for occupational therapy training programmes. Additionally, rural service learning placements may contribute to preparing students to work in rural settings when they are employed by the SA Department of Health as community service occupational therapists. However, given the urban location of most universities in South Africa, service learning in rural communities requires extensive additional resources, including financial resources and time, as students and service learning educators typically need to travel long distances and be accommodated in these communities during service learning placements.

It is therefore necessary to ascertain whether rural service learning placements hold the same benefits for occupational therapy students as has been evidenced in service learning literature in general; and whether the value of a rural service learning placement to students is potentially different to placements in an urban setting. Evidence of the value of a rural service learning experience for occupational therapy students may enable occupational therapy departments ${ }^{a}$ to weigh the potential costs and benefits of rural service learning engagements in order to make informed decisions about aspects such as resource allocation and student practice learning.

\section{LITERATURE REVIEW}

A review of the literature that explores change mechanisms within the pedagogy of service learning; that is, mechanisms through which students are encouraged to learn, develop and grow through service learning, is provided to support the interpretation of students' articulation of the value of a rural service learning experience. This will be the focus of the first part of the literature review. There-

a Universities use different terms to refer to what the UFS terms 'department', such as 'division' or 'school'. 
after, the unique characteristics and challenges of the rural setting are explored briefly to provide a contextual background and an understanding of the value of a rural service learning experience.

\section{The pedagogy of service learning: Mechanisms for change}

Service learning is rooted in the theories of constructivism and experiential learning. Dewey's belief in the value of experience to facilitate learning through the learner's active engagement and reflection provides the most fundamental theoretical grounding for the pedagogy of service learning ${ }^{15,16}$ Kolb $^{17}$ expanded on the theories of Dewey, Lewin and Piaget; further developing the theory of experiential learning and defining it as "the process whereby knowledge is created through the transformation of experience. Knowledge results from the combination of grasping and transforming experience" ${ }^{17: 41}$. Kolb theorised in his renowned experiential learning cycle that experience provides the basis for observation and reflection from which abstract conceptualisations can be assimilated, and active experimentation with concepts in new situations can be generated to guide new experiences ${ }^{18}$.

Contemporary conceptualisations of service learning also note the potential for transformative learning ${ }^{4,19,20,21}$. Kiely's Transformational Service-Learning Process Model explains “... how different types and levels of dissonance lead to different modes of learning ... [and] identify[ing] a connection between contextual factors and multiple forms of dissonance"21:15. The model consists of five themes, namely contextual border-crossing, dissonance, personalising, processing and connecting. Contextual border-crossing refers to different contextual elements or 'borders' (such as personal, structural or historic) that, when crossed, cause students to reappraise their own worldviews. Dissonance refers to tension between a student's prior worldview and the contextual factors that characterise the service learning experience. The nature of the dissonance affects the resulting learning process. Personalising refers to students' individual responses to dissonance that require students to appraise their personal strengths and weaknesses. Processing requires both individual reflection and social dialogue. Processing enables the student to problematise, analyse and search for solutions to the challenges experienced. Finally, connecting entails non-reflective, emotive learning that enables the student to understand and empathise with different role players in the service learning experience. Kiely's model thus illustrates the mechanisms through which transformational learning takes place during service learning, which provides an interpretive lens through which the students' values attached to their experiences, can be viewed.

\section{The rural setting: Unique characteristics and challenges}

A precise definition for the term rural seems elusive - definitions range from "any area that is not classified as urban"22:18 to definitions that classify areas as rural or urban depending on access to resources ${ }^{23}$. For the purpose of this article, the latter definition is used.

Rural areas are distinct from urban areas in many ways, but none more pervasive than the difference in availability of resources. According to StatsSA's 2002 report on "Measuring Rural Development" and the 2014 "General Household Survey", people living in rural areas in South Africa have a much higher unemployment rate, less access to basic services such as water, electricity and sanitation, less access to health care and other services, and a significantly higher number of households that are dependent on social grants as their only source of income when compared to the figures for the country as a whole ${ }^{22,24}$. These challenges not only provide a practice setting completely different to settings that students are usually exposed to (i.e. urban settings), but also afford students unique opportunities for academic, professional, personal and civic growth. For example, a study conducted at the University of Cape Town (UCT) among third year occupational therapy students demonstrated that a rural service learning experience helped students to better understand the dynamics of working in a community, and afforded them with opportunities for professional development and development of personal competencies ${ }^{25}$.

There were however, many factors (such as the year of study, duration of placement and nature of supervision) in the cited study that differed from the university where this study was conducted. Since these factors influence transformative learning dimensions such as contextual border-crossing and processing, exploring the value of a rural service learning experience for final year undergraduate occupational therapy students at the University of the Free State remained paramount in order to further elucidate how a rural service learning experience benefits occupational therapy students - potentially in a way that is distinct from urban service learning experiences.

\section{RESEARCH CONTEXT}

At the time this study was conducted, final year undergraduate occupational therapy students (hereafter 'students') from the University of the Free State (UFS) were placed in a rural service learning block of five to six weeks in the Southern Free State (SFS) towns of Philippolis, Trompsburg and Springfontein. Three students were placed in the SFS at a time, and lived in a student house from Monday to Thursday, returning to Bloemfontein each weekend. The student house was administered by the Khula-Xhariep Partnership (KXP), a Non-Profit Company (NPC) established in 2008 as a result of a community engagement partnership formed between this SFS community and the UFS. There were four placement periods per year, resulting in twelve students visiting the SFS for a service learning placement in a calendar year.

Service learning in the SFS formed part of the final year students' clinical fieldwork module. A service learning placement in either an urban community setting or a rural community setting in the SFS, contributed $25 \%$ to the formative mark of this module. For this part of the module, students were expected to integrate curricular knowledge pertaining to community-based practice in occupational therapy, occupational therapy management, as well as general occupational therapy theory and clinical skills.

Service activities in the SFS were determined by the community service needs as identified by the community representatives, and could change significantly from one placement to the other. It was therefore not the nature of the service activities that was investigated, but the unique (rural) setting that these activities took place in.

Reflection in this module was facilitated by weekly, unstructured journals that students submitted electronically (via e-mail) to the service learning educator (the first author). The service learning educator also facilitated verbal reflection ('social dialogue') ${ }^{21}$ with students during site visits that took place at least twice per placement.

The collaborative nature of the partnership was maintained through regular personal contact between the service learning educator, students and the community representatives during site visits, as well as attendance at KXP meetings by the service learning educator (and students when possible). The aims of the partnership and students' service activities were negotiated collaboratively between all parties concerned on a regular basis.

The SFS/KXP service learning partnership was established three years prior to conducting this study, and the university wanted to review and reconsider the funding and continuation of future rural service learning placements. Although various gains were reported by students to UFS staff and service learning educators, a systematic exploration would highlight further gains to undergraduate learning experiences for practice within the South African context in future.

\section{METHOD}

A qualitative, descriptive enquiry design was employed to describe the value of a rural service learning experience for the final year undergraduate occupational therapy students at the University of the Free State. This design is deemed suitable when attempting to 
describe people's experiences of life events ${ }^{26}$, and in the context of this study, students' experiences of a rural service learning placement and the value they ascribed to it. Ethical approval for the study was obtained from the Research Ethics Committee of the Faculty of Health Sciences at the UFS (ETOVS No. 169/20I I). Permission for the study was granted by university authorities and students gave voluntary informed consent for participation in the study.

Twelve white, female students who had experienced a rural service learning placement in one year were purposively sampled for inclusion in the study population. The study was conducted in the December of the students' final year of study and after their final examinations, so as to ensure recent exposure to the rural service learning experience and to allow for inclusion of all of the students who had participated in the rural service learning placement during that year. All students who gave voluntary informed consent, complied with the inclusion criteria that specified experience of a rural service learning placement and proficiency in Afrikaans or English, and who were available at the scheduled time for participation, were included in the study.

Two types of data sources were used, namely the prioritised statements from a nominal group technique facilitated during a group session, and students' written reflective journals. Nine students were available for participation in the group session, while all twelve students' journals were included in the study. The length of journals ranged between four and eight pages.

A nominal group technique ${ }^{27,28}$ was facilitated during the group session with the students, owing to its advantages of being costand time effective, a less threatening data collection tool than, for example, personal interviews and for indicating priorities through voting opportunities. The nominal group technique was facilitated by an external, trained facilitator. The group was conducted at the UFS at a time that was convenient for the students. Figure $I$ outlines the steps followed during the nominal group technique. The question posed for the nominal group process was: "What was the value of your rural service learning experience?"

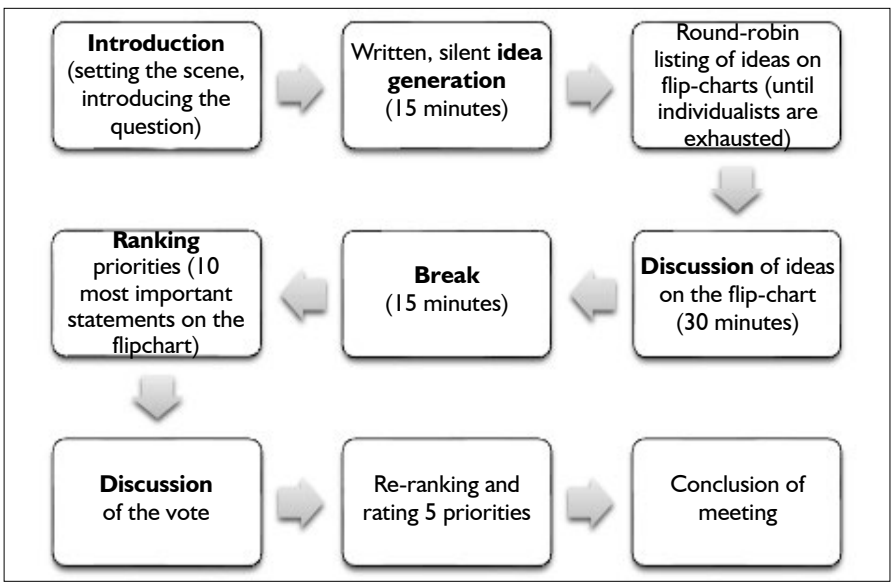

Figure I: Steps followed during the Nominal Group Process (Figure constructed from Van Den Ven and Delbecq $^{27}$ )

Secondly, all students kept a weekly journal of their experiences during their rural service learning placements. These journals were submitted to the service learning educator electronically (via e-mail) each week, as well as on a CD-ROM at the end of the service learning block. A deductive (a priori) qualitative content analysis of these journals was performed in order to triangulate the findings of the nominal group as they manifested during students' service learning experiences. The five statements prioritised during the nominal group process served as the a priori codes according to which the journals were analysed independently by the two authors. All personally identifiable information was removed from the journals by the service learning educator prior to data analysis to ensure confidentiality of the information.
The trustworthiness ${ }^{29}$ of the data, particularly the credibility thereof, was enhanced by making use of method triangulation (i.e. nominal group technique and deductive content analysis of journals) as well as investigator triangulation (i.e. the nominal group was facilitated by an external facilitator and coding of journals was done by the two authors independently). Accounting for changing conditions in order to promote dependability was primarily done through analysis of the students' journals, which not only described their reflections but also the specific events that shaped their experiences. An audit trail of data collection and analysis processes contributed to the confirmability of the data.

\section{RESULTS}

A list of 27 statements was generated during the group discussion. Students then prioritised five statements as most representative of the value of their rural service learning experience. The five statements were as follows:

- I learned to work with people on their level, and not from the top.

- Ilearned about the role of the occupational therapist to empower the community, so that the community can function more independently.

- I have learned a lot about the practical implications of working in a community setting.

- I have learned how much longer things take in a community setting.

- I have learned to utilise my personal strengths optimally and to overcome my personal challenges so that I don't become my own obstacle.

Each of these statements could be connected to the reflections in the students' journals through a priori coding, yielding similar themes and thus providing triangulation of the results; hence the results of the nominal group technique and analysis of the students' journals are presented concurrently.

\section{"I learned to work with people on their level, and not from the top."}

During nominal group discussions, students elucidated this statement with explanations that they had learned to act as facilitators rather than teachers or educators; facilitating a process through which the community members were able to access their own assets and 'indigenous knowledge' rather than taking on the role of expert imposing profession-specific knowledge onto the community. Students voiced their experience of this more collaborative approach as being more sustainable and valuable to both the community and the student.

Students' journals reflected numerous experiences of collaboration with community members, which seem to have catalysed this learning. For example, one student reflected (emphasis added by the authors):

... I had the chance to give a bit more attention to other needs that [the manager] had, like ... personalising the Old Age Home ... Today [I] worked with [the manager] to think of a nice idea to make the Old Age Home more personal and to help to know some of the elderly a little better without struggling. We want to compile a document with the basic information about the resident ... and thought to place a pretty photo frame and name board on each resident's door.

\section{"I learned about the role of the occupational therapist to empower the community, so that the community can function more independently."}

Having had most of their clinical experience in hospital or institution-based settings, students found the community setting a challenging one to work in, and one in which the boundaries of the scope of practice between professions are much more blurred. For students to voice an experience of an enhanced 
sense of the role of the occupational therapist in the community, however restricted the articulation of this role may seem, was very empowering.

In their journals, students often expressed initial confusion regarding their role, such as: "I struggle to determine exactly what is needed in terms of occupational therapy goals." This was, however, often followed in later writings by expressions of greater clarity regarding their roles as future occupational therapists, for example: "This week I learned a lot about myself but also about our profession and specifically our profession in a home for the elderly."

In addition, students also reflected in their journals on how they experienced 'empowerment' of community members as a natural progression of their service learning activities. One student wrote the following observation during the course of a collaborative vegetable gardening project at a school in the community:

Excitement, potential and [their] need for 'ownership' are some of the thoughts associated with the [school]. After meeting the staff and introducing the proposed project, [we] planned how to tackle it...

The Grade 8 group practised their problem solving skills with the planning of necessities for the vegetable garden and choosing a name for the growing piece of land themselves. It was so cool to see, how a simple activity enhances cohesion in the group and improves internal motivation with the development of 'ownership' for 'Metro Veg' [the vegetable garden project].

It was encouraging that students experienced the reciprocal power of empowerment. Collaborative efforts between the students and community members led to valuable learning experiences through which the students did not only see the impact of their involvement but also experienced personal development:

I was also sad because you grow to love the residents. You get to know them, I learned so much from them about myself as a person and it was really a positive learning experience. I also grew a lot professionally and enjoyed it a lot.

\section{"I have learned a lot about the practical implications of working in a community setting."}

The students explained during nominal group discussions that the demands on their ability to integrate theory with practice were very high, owing to the diverse nature of activities in which they were involved in the rural community setting. They also experienced greater demands on their management skills, as the students were required to take primary responsibility for the management of the service in this rural setting. The students indicated that they gained hands-on experience of factors that influence the feasibility of a project or action in the community, and factors that could enhance the feasibility of community projects; mostly based on the close collaboration between community representatives and the students.

The same sentiments regarding integration of theory and practice, managerial demands and factors influencing the effectiveness of efforts in the community appeared in students' journals, as the following two excerpts exemplify:

I sharpened my knowledge about stroke and I learned how to do training sessions. I learned what will work better than what I did.

. I did a lot of reading about visual perception and the development of writing skills ... this reading serves as a good basis for my [project]. This week was productive, because I now feel familiar with ... the staff, the children and the routine of the school. I can now compile an effective week programme for next week.

The most pertinent reflection about the practical implications of working in the community related to time management - students' journals were replete with reflections regarding the need for effective time management, for example: "All it cost was thorough planning and I could do it in two hours," and "During this week I again realised the importance of time management."

Closely related to findings regarding time management, was the fourth statement that students prioritised during the group, namely:

\section{"I have learned how much longer things take in a community setting."}

During the research group discussions, as well as in their journals, students expressed some frustration with the lack of resources they experienced in the rural community setting. Factors such as power outages for days, weak signal for internet access, lack of access to facilities such as academic libraries and a general difficulty with access to resources were highlighted by students, which they felt impaired their ability to manage their time effectively in the rural community setting. The following excerpt from a student's journal illustrates the frustrations and resulting impact on students' efficacy:

The limited resources break me, I want to make cute things for spring day ... but the big question is ... WITH WHAT?

Frustration with long hours on the road taking up valuable time was also highlighted both during the research group and in students' journals, for example:

[We] have found that planning is somewhat complicated by the fact that we spend many hours on the road and we are going to try to help one another as far as possible to have optimal time in each of our areas.

The reality of the impact of logistical challenges in the community itself, such as the community members' own lack of resources such as reliable transportation also confronted students:

There-after I went back to Trompsburg; the twins could, however, not come for therapy today as a result of transportation problems.

Although these findings do not seem to speak directly to the value of a rural service learning experience, it became apparent during the nominal group technique that it was the ability to manage, work with, learn about and overcome these challenges that students valued.

\section{“I have learned to utilise my personal strengths optimally and to overcome my personal challenges so that I don't become my own obstacle."}

All the students expressed a high intensity of being challenged on a personal level while living in the SFS. Students were removed from their familiar surroundings, had to share a room and/or a house with fellow students and had to take primary responsibility for what they would be doing every day. Specific personal skills students highlighted as having been enhanced included planning, assertiveness, adaptability, independent thinking and reasoning, self-knowledge (including identifying fields of professional interest) and valuing the resources at their disposal.

All of these sentiments were also reflected in students' journal entries, some of which are presented below (emphasis added by the authors to highlight key concepts):

... it is an adjustment to be away from my own home and to stay with two other students.

I learned to be more patient with the handling of Ms. A. I realised that I will have to keep more of a professional distance when working with residents, otherwise I get upset...

There my planning also turned out differently. I saw a group and when I wanted to see the next group, the whole class arrived! I had to improvise quickly, but believe that it was still a successful session.

Initially I was very scared of the whole experience, because you are taken out of your comfort zone, but I grew and I lived. This area made me realise so much - personally and professionally. And I am grateful that I could go through this 'community experience'.

\section{DISCUSSION}

The results of this study demonstrated the students' transformative learning experiences ${ }^{21}$ during a rural service learning placement. 
Contextual border-crossing was evident in many of the students' comments, most notably those relating to students having to live away from their familiar surroundings and resources, and engaging with people who are 'different' from them (e.g. with respect to age, race or background). Dissonance was apparent in the students' discomfort with aspects of the contextual border-crossing, often causing them to reappraise previously-held assumptions (e.g. surprise about the community's capacity for ownership) but in some cases also reinforcing stereotypical handling (such as maintaining a 'professional distance'). Dissonance caused by the living arrangements in the student house away from the students' 'comfort zone' also emerged as a pervasive contributor to students' transformative learning processes. It was further evident that exposure to the service learning experience facilitated personalising - demonstrated most aptly in the fifth prioritised nominal group statement, namely: "I have learned to utilise my personal strengths optimally and to overcome my personal challenges so that I don't become my own obstacle." Evidence of processing was present in both students' journal entries and their discussions during the nominal group process. However, it is the service learning educator and first author's opinion that reflective and dialogic techniques to facilitate processing in this service learning module were not optimal (journals were mostly unstructured; often not optimally eliciting reflection but rather simply re-telling of experiences, and opportunities for facilitating social dialogue was limited as the service learning educator only engaged with students face to face in the community twice during a placement). Finally, the findings demonstrated that students connected through emotive learning on various levels. Emotions like fear, sadness, excitement and joy surfaced regularly in the students' journal entries and helped students to foster a sense of connectedness with community members.

It appears, therefore, that the experience of a rural service learning placement was indeed one of transformative learning, and that this transformative learning was where the value of the experience was situated for students. It is striking to note that all of the five prioritised statements during the nominal group started with the words "I (have) learned ..."

The findings of this study correlated well with the findings of Adams and Wonnacott ${ }^{25}$ indicating that a rural service learning experience helped students to better understand the dynamics of working in a community, corresponding with findings relating to learning about the unique nature and ethos of community-based practice in occupational therapy and findings relating to learning about the challenges and realities of working in a rural community setting in this study. Other studies among occupational therapy students have also demonstrated that participation in service learning (not necessarily in rural areas) enhanced students' knowledge of the scope of occupational therapy ${ }^{8}$ and their skills in working in community settings ${ }^{7}$.

The findings of this study further corroborated those of Adams and Wonnacott ${ }^{25}$ who found that a rural service learning experience afforded students with opportunities for development of professional and personal competencies, corresponding with findings relating to developing personal capacities in this study. Other studies among occupational therapy students have also drawn similar conclusions regarding the value of service learning experiences ${ }^{7,8,9}$.

The results of this study are also congruent with findings in service learning literature outside of the profession of occupational therapy that suggest positive contributions to students' academic, professional and personal growth ${ }^{2,3,4,5}$. This study did not yield specific evidence for the development of social responsibility among students as a result of a rural service learning experience; however, Maloney et al. ${ }^{8}$ suggest that the development of professional and personal capacities and an enhanced awareness of social issues provide students with the means to address these issues in a socially responsive manner in future. These findings may point to a need for further investigation into the dynamics involved in the development of social responsivity through service learning in a rural community setting for occupational therapy students.

Although the study was designed to describe the value of a rural service learning experience for final year undergraduate occupational therapy students, not all of the findings of the study yielded conclusive evidence of the of the implications of 'rurality' on the value of the experience for students. Not all of the students' articulations of the value of their experiences related directly to the rural setting, and it could be argued that the 'value' of the service learning experiences described by students may have been similar in urban community settings (such as learning about the role and ethos of community-based practice in occupational therapy).

However, the unique characteristics of the rural setting, including the dire lack of resources, increased travelling time and being out of their 'comfort zones' perceptibly increased the intensity of contextual border-crossing and dissonance that students experienced. Kiely ${ }^{21}$ demonstrated that the intensity of dissonance experienced by the student mediates the resulting learning, with high-intensity dissonance causing ongoing learning. The findings of this study, therefore, suggest that the value students derived from learning about the challenges and realities of working in a rural community setting, and developing personal capacities, were enhanced by the rural service learning experience.

Owing to its qualitative nature, this study was bound by a specific context and as such the results of the study may not be generalisable to all rural service learning experiences that occupational therapy students may be exposed to. However, the transferability of the results was enhanced by a comprehensive description of the research context whereby applicability to another setting may be estimated. There was also good correspondence between the findings of this study and another similar, yet contextually different, study ${ }^{25}$, further promoting transferability of results.

\section{IMPLICATIONS AND CONCLUSION}

The implications of this study for occupational therapy departments when making decisions regarding resource allocation and student practice learning bring to mind two primary considerations.

Firstly, the intended learning outcomes targeted by the rural service learning experience would be a deciding factor. Students may well be able to learn about 'how' to work in communities in any community-based practice setting. However, if outcomes relate more to dealing with challenges (such as resource-scarcity) and developing professional and personal competencies (such as managerial skills and independent reasoning), a rural service learning placement, away from the luxuries and accessibility of resources in the urban setting, seems to meaningfully enhance the intensity of the transformative learning experience for students.

Secondly, universities (and individual departments) may wish to consider their own stance toward the imperative to extend university resources to under-resourced communities; the most direly affected of which are undoubtedly the rural communities in South Africa. Taking the call for social responsiveness seriously may prompt universities (and individual departments) to invest more extensively in rural communities, even if students could achieve similar learning outcomes in urban settings at a relatively lower cost.

This study pointed to a need for further investigation into the development of occupational therapy students' social responsibility through rural service learning experiences. In future, it may also be worthwhile to undertake comparative studies that investigate the effects of rural vis-a-viz urban service learning placements on occupational therapy students' development.

The rural service learning experience contributed to meaningful and transformational learning for final year undergraduate occupational therapy students in this study. Investing in these learning experiences to the benefit of students and rural communities alike seems to be a worthwhile endeavour for occupational therapy training programmes in South Africa. 


\section{ACKNOWLEDGEMENTS}

Dr Deirdre van Jaarsveldt, School of Nursing, University of the Free State, for facilitating the nominal group process.

Dr Christel Troskie-de Bruin, for constructive inputs during the preparation of the manuscript for publication.

\section{REFERENCES}

I. Duncan M, Alsop A. Practice and Service Learning in Context, Chapter I. In Practice and Service Learning in Occupational Therapy - Enhancing potential in context. Edited by Lorenzo T, Duncan M, Buchanan H, Alsop A. West Sussex: Whurr Publishers Limited, 2006: 7-16.

2. Bringle RG, Clayton PH, Hatcher JA. Research on Service Learning An Introduction, Chapter I. In Research on Service Learning Conceptual Frameworks and Assessment Volume 2B: Communities, Institutions and Partnerships. Edited by Clayton PH, Bringle RG, Hatcher JA. Sterling: Stylus Publishing, LCC, 20I3: 3-26.

3. Felten P, Clayton PH. Service-Learning. New Directions for Teaching and Learning. 20I I; Winter (I28): 75-84.

4. Petersen N, Osman R. An introduction to service learning in South Africa, Chapter I. In Service Learning in South Africa. Edited by Osman R, Petersen N. Cape Town: Oxford University Press Southern Africa (Pty) Ltd., 2013: 2-32.

5. University of the Free State. Community Service Policy (Policy 06. I). Bloemfontein: University of the Free State, 2006.

6. Eyler J. What international service learning research can learn from research on service learning, Chapter 10. In International Service Learning: Conceptual Frameworks and Research. Edited by Bringle RG, Hatcher JA, Jones SG. Sterling: Stylus Publishing, LLC, 2010: 225-24I.

7. Horowitz BP, Wong SD, Dechello K. Intergenerational service learning: to promote active aging, and occupational therapy gerontology practice. Gerontology \& Geriatrics Education. 2010; $3 \mathrm{I}(\mathrm{I}): 75-9 \mathrm{I}$.

8. Maloney SM, Myers C, Bazyk J. The Influence of a CommunityBased Service-Learning Experience on the Development of Occupational Therapy Students' Feelings of Civic Responsibility. Occupational Therapy in Mental Health. 20I4; 30(2): 144-I6I.

9. Schindler VP (20I4). Community engagement: outcomes for occupational therapy students, faculty and clients. Occupational Therapy International. 20I4; 2 I (2): 7I-80.

10. Higher Education Quality Committee. Criteria for Programme Accreditation. Pretoria: Council on Higher Education, 2004.

II. Stanton TK, Erasmus MA. Inside Out, Outside In: A Comparative Analysis of Service-Learning's Development in the United States and South Africa. Journal of Higher Education Outreach and Engagement. 2013; 17(1): 63-96.

12. World Health Organization (WHO). Bridging the gap in South Africa. Bulletin of the World Health Organization. 2010; 88(II): 797876. <http://www.who.int/bulletin/volumes/88/I I/I0-021 II0/ en/> (30 September 20I5)

13. Day C, Gray A. Health and Related Indicators. In: Padarath A, English R (Eds). South African Health Review, 2013/I4. Durban: Health Systems Trust, 2014. <http://www.hst.org.za/publications/ south-african-health-review-20I3/I4> (30 September 20I5)

14. Department of Health. "Conference on Health in Rural Nodes Conference Opening Speech.” 2004. <http://www.doh.gov.za/ show.php?id=824> (29 October 20I I)

15. Dewey J. Experience \& Education. New York: Kappa Delta, 1938.

16. Dewey J. Experience and Education. New York: Collier, 1963.

17. Kolb DA. Experiential Learning. Englewood Cliffs: Prentice-Hall, Inc., 1984.

18. Kolb DA, Boyatzis RE, Mainemelis C. Experiential Learning Theory: Previous Research and New Directions, Chapter 9. In Perspectives on Thinking, Learning, and Cognitive Styles. Edited by R. J. Sternberg RJ, Zhang L. New York: Lawrence Erlbaum Associates, Inc., 2001: 227-248.

19. Bamber P, Hankin L. Transformative learning through servicelearning: no passport required. Education and Training, 20I I; 53(2/3): 190-206.

20. Butin DW. Service-Learning in Theory and Practice - The Future of Community Engagement in Higher Education. New York: Palgrave
MacMillan, 2010.

21. Kiely R. A Transformative Learning Model for Service Learning: A Longitudinal Case Study. Michigan Journal of Community Service Learning. 2005; Fall: 5-22.

22. Statistics South Africa. Measuring rural development - Baseline statistics for the integrated sustainable rural development strategy. 2002. Pretoria: Statistics South Africa. <http://www.statssa.gov. $\mathrm{za}$ /publications/RuralDevelopment/RuralDevelopment.pdf > (29 October 20II).

23. Department of Health. A Rural Health Strategy for South Africa. Draft for discussion 2 March 2006. 2006. <http://www.rudasa. org.za/papers.php> (29 October 20II).

24. Statistics South Africa. General household survey 2014. 2015. Pretoria: Statistics South Africa. <http://www.statssa.gov.za/ publications/P03 I8/P03 I820 I4.pdf > (8 February 20I6).

25. Adams F, Wonnacott H. Group Learning Experiences in Rural Communities, Chapter 8. In Practice and Service Learning in Occupational Therapy - Enhancing potential in context. Edited by Lorenzo T, Duncan M, Buchanan H, Alsop A. West Sussex: Whurr Publishers Limited, 2006: I I8-13।.

26. Botma Y, Greeff M, Mulaudzi FM, Wright SCD. Research in Health Sciences. Cape Town: Pearson Education South Africa (Pty) Ltd., 2010.

27. Van den Ven AH, Delbecq AL. The Nominal Group as a Research Instrument for Exploratory Health Studies. American Journal of Public Health. 1972; March: 337-342.

28. Cohen L, Lawrence M, Morrison K. Research methods in education. 6th ed. New York: Routledge, 2009.

29. Schurink W, Fouché CB, De Vos AS. Qualitative data analysis and interpretation, Chapter 24. In Research at Grass Roots For the Social Sciences and Human Service Professions, 4th ed. Edited by De Vos AS, Strydom H, Fouché CB, Delport CSL. Pretoria: Van Schaik Publishers, 201 I: 397-430.

\section{Corresponding author}

Elize Janse van Rensburg JanseVanRensburgE@ufs.ac.za 